\title{
ERRATUM \\ The prediction of live weight from body measurements on female Holstein calves by digital image analysis - ERRATUM
}

\section{S. OZKAYA}

DOI: http://dx.doi.org/10.1017/S002185961200086X, published by Cambridge University Press, 15 November 2012.

In the Materials and Methods, sub-section headed Statistical analysis, the two equations given are not correct. They should read:

$Y=b_{0}+b_{1} X_{1}+b_{2} X_{2}+\ldots+b_{n} X_{n}+e_{i j}$

and

$Y_{i}=b_{0}+b_{1} X_{i}+b_{2} X_{i}^{2}+b_{3} X_{i}^{3}+e_{i}$

\section{REFERENCE}

S. OZKayA (2012). The prediction of live weight from body measurements on female Holstein calves by digital image analysis. Journal of Agricultural Science, Cambridge, http://dx.doi.org/10.1017/S002185961200086X. 